\title{
Induction of mitochondrion-mediated apoptosis of CHO cells by tripchloro- lide
}

\author{
YAN REN, LEI XIONG, JIA RUI WU* \\ Laboratory of Molecular Cell Biology, Institute of Biochemistry and Cell Biology, Shanghai Institutes for Biological \\ Sciences, Chinese Academy of Sciences, 320 Yue Yang Road, Shanghai 200031, China
}

\begin{abstract}
Tripchlorolide (TC) is a potent antitumor reagent purified from a Chinese herb Tripterygium Wilfordii Hook. f.. However, its cellular effects and mechanism of action are unknown. We showed here that TC induced apoptosis of Chinese Hamster Ovary ( $\mathrm{CHO}$ ) cells in time- and dose-dependent manners. TC resulted in the degradation of Bcl-2, the translocation of Bax from the cytosol to mitochondria, and the release of cytochrome c from mitochondria. Stable overexpression of human Bcl-2 could reduce the apoptosis of TC-treated cells by blocking the translocation of Bax and the release of cytochrome c. These results indicate that TC induces apoptosis of $\mathrm{CHO}$ cell by activating the mitochondrion-mediated apoptotic pathway involving the proteins of Bcl-2 family and cytochrome c.
\end{abstract}

Key words: apoptosis, mitochondrial pathway, $\mathrm{CHO}$ cell.

\section{INTRODUCTION}

Apoptosis as an intrinsic suicide serves to remove excess, damaged or infected cells in metazoans. It's known that apoptosis is characterized by a variety of morphological and biochemical events, including phosphatidylserine (PS) externalization, chromatin condensation, genomic DNA fragmentation, and plasma-membrane blebbing[1, 2]. It has been shown that mitochondria play a key role in apoptotic control $[3,4]$. Bcl-2 family proteins, which are subdivided into either anti-apoptotic members such as Bcl-2 and Bcl$\mathrm{XL}$ or pro-apoptotic members such as Bax and Bak, constitute critical components of the mitochondrial

\footnotetext{
* Correspondence: Prof. Jia Rui WU

Institute of Biochemistry and Cell Biology, Shanghai Institutes for Biological Sciences, Chinese Academy of Sciences, 320 Yue Yang Road, Shanghai 200031, China Tel: 0086-21-54921128

Fax: 0086-21-54921011Ｅ-mail:wujr@sibs.ac.cn

Abbreviations: CHO, Chinese hamster ovary; TC, tripchloro- lide; PI, propidium iodide.

Received Nov-07-2002 Revised June-20-2003 Accepted June-222003
}

apoptotic signaling pathway[5-7]. One of key targets for Bcl-2 family proteins is the control of cytochrome $\mathrm{c}$ release from mitochondria[6], which leads to the activation of caspases[8].

Tripchlorolide (TC) is a compound isolated from extracts of Tripterygium Wilfordii Hook. f., which shows anti-inflammatory, immunosuppressive, antifertility and antitumor activities[9-11]. Recently, some experiments have shown that a derivative of TC, triptolide, can block p21-mediated growth arrest and then enhance chemotherapy-induced apoptosis in tumor cells, or cooperate with tumor necrosis factor-a to induce apoptosis in tumor cells[12, 13].

In this study, we analyzed the apoptotic effect of TC on mammalian cells. TC induced apoptosis of Chinese hamster ovary $(\mathrm{CHO})$ cells in time- and dosedependent manners. Furthermore, cytochrome c was released from mitochondria in the drug-treated $\mathrm{CHO}$ cells, which was tightly correlated with Bax translocation from cytosol to mitochondria, and Bcl-2 degradation. The process of TC-induced apoptosis 
could be partially blocked by overexpression of Bcl-2.

\section{MATERIALS AND METHODS}

\section{Cell culture}

CHOC400 cells were maintained in Dulbecco's Modified Eagle's Medium (DMEM) supplemented with $50 \mu \mathrm{g} / \mathrm{ml}$ streptomycin, $50 \mathrm{U} /$ $\mathrm{ml}$ penicillin and $100 \mathrm{mM}$ non-essential amino acids at $37^{\circ} \mathrm{C}$ in $5 \%$ $\mathrm{CO}_{2}$. All regents used in the cell culture were purchased from GIBCO BRL.

\section{Plasmids and DNA transfection}

pEGFP-C1-Bcl-2 expressing Bcl-2-EGFP fusion protein under control of the cytomegalovirus promoter was constructed by inserting full-length human bcl-2 cDNA into the vector pEGFP-C1 (CLONTECH). CHOC400 cells $\left(2 \times 10^{5}\right)$ were transfected with pEGFP-C1-Bcl-2 by lipofectamine ${ }^{\mathrm{TM}} 2000$ system (GIBCO BRL). Then the cells were selected in the DMEM medium in the presence of $2000 \mu \mathrm{g} / \mathrm{ml} \mathrm{G} 418$ for approximate 10 days.

Preparation of cytosol extracts by digitonin permeabilization

CHOC400 cells $\left(1.5 \times 10^{6}\right)$ were harvested, and resuspended in $100 \mathrm{ml}$ of transport buffer ( $20 \mathrm{~m} M$ Hepes-KOH, pH 7.3, $110 \mathrm{mM} \mathrm{KAc}$, $5 \mathrm{~m} M \mathrm{NaAc}, 2 \mathrm{~m} M \mathrm{MgAc}_{2}, 1 \mathrm{~m} M$ EGTA) containing $200 \mu \mathrm{g} / \mathrm{ml}$ digitonin, and then incubated on ice for $10 \mathrm{~min}$. The cell lysates were centrifugated at $10,000 \mathrm{~g}$ at $4^{\circ} \mathrm{C}$ for $15 \mathrm{~min}$. The supernatants were collected as cytosolic fractions and the pellets were mitochondrioncontaining fractions.

\section{SDS PAGE and western blot analysis}

The whole cells $\left(1.5 \times 10^{6}\right)$ were lysed in $200 \mathrm{ml}$ of $1 \times$ SDS-sample buffer (1× SDS-sample buffer: $50 \mathrm{~m} M$ Tris-Cl, $\mathrm{pH}$ 6.8, $100 \mathrm{mM}$ DTT, $2 \%$ SDS, $10 \%$ glycerol and $0.1 \%$ bromophenol blue). In the case of digitonin-permeabilized cells, the supernatants were mixed with equal volume of $2 \times$ SDS-sample buffer, and the pellets were solubilized in two volumes of $1 \times$ SDS-sample buffer. The amount of proteins from equal number of cells $\left(5 \times 10^{6}\right.$ for Bcl- $2,1 \times 10^{6}$ for other proteins) was subjected to SDS-PAGE gels. Immunoblotting was carried out with appropriate primary antibodies (anti-Bax and anti-Cytochrome c from Santa Cruz; anti-Bcl-2 from Sigma; antiCOX 4 from Molecular Probes; 1:500 dilution for Bcl-2, 1:1000 dilution for others) and secondary antibodies. Immune complexes were detected by the enhanced chemiluminescence system according to the manufacturer's instructions (ECL, Amersham).

\section{Flow cytometric analysis (FACS)}

The cells were harvested and fixed with $70 \%$ ethanol. The cells were then incubated with $500 \mu \mathrm{g} / \mathrm{ml}$ RNase at $37^{\circ} \mathrm{C}$ for $30 \mathrm{~min}$ and stained with $20 \mu \mathrm{g} / \mathrm{ml}$ propidium iodide (PI, Sigma). The cell samples were analyzed by the flow cytometer (FACScan, Becton Dickinson).

DNA fragmentation assay
CHOC400 cells $\left(5 \times 10^{6}\right)$ were harvested and incubated in $500 \mu \mathrm{l}$ of cell-lysis buffer (10 m $M$ Tris-Cl, pH 8.0, $25 \mathrm{~m} M$ EDTA, 0.25\% Triton X-100) on ice for $30 \mathrm{~min}$. The lysates were centrifugated at $13,500 \mathrm{~g}$. After the centrifugation, the supernatants were collected and incubated with $100 \mu \mathrm{g} / \mathrm{ml} \mathrm{RNase}$ at $37^{\circ} \mathrm{C}$ for $30 \mathrm{~min}$, and then with $200 \mu \mathrm{g} / \mathrm{ml}$ proteinase $\mathrm{K}$ at $56^{\circ} \mathrm{C}$ overnight. The mixtures were extracted sequentially with phenol and chloroform, and then precipitated with ethanol. Pellets were resuspended in Tris-EDTA buffer and electrophoresed on a $1.5 \%$ agarose gel.

\section{Annexin V-PI double staining and MTT assay}

CHOC400 cells $\left(1 \times 10^{5}\right)$ were treated with TC and incubated with Annexin V-FITC and PI according to the manufacturer's instructions (PharMingen). Samples were analyzed by the flow cytometer. The viability of cells was measured by MTT assay according to the manufacturer's protocol (Sigma).

\section{RESULTS}

\section{TC induced apoptosis of CHOC4OO cells}

To investigate effects of TC on the cell viability, exponentially growing CHOC400 cells were administered with TC. Flow cytometric analysis showed that a cell population containing a sub-G1 DNA content (below the G0/G1 peak) appeared by $24 \mathrm{~h}$ of TC treatment, and increased to about $60 \%$ by $48 \mathrm{~h}$ (Fig 1A). The DNA ladder was also detected in the TCtreated CHO cells (Fig 1B), which is a well-known hallmark of apoptosis[14]. Since phosphatidylserine turns over from inside to outside of plasma membrane at the early stage of apoptosis, which can be detected by Annexin V assay[15], the CHO cells with or without the treatment of TC were analyzed by Annexin V-PI double staining. The results showed that the apoptotic cell population of TC-treated cells (in rightbottom area of Fig 1C), which are Annexin V-positive and PI-negative, increased significantly. Taken together, these results demonstrated that TC induced apoptosis of CHO cells.

\section{TC-induced apoptosis was time- and dose-dependent}

In order to analyze the kinetics of TC-induced apoptosis, we exposed the exponential CHOC400 cells to TC for different durations. The result from Annexin $\mathrm{V}$ assay revealed that the induction of apoptosis was dependent on the durations of TC treatment in a linear fashion (Fig 2A). Furthermore, the similar results were detected when CHOC400 cells were treated with $\mathrm{TC}$ at different concentrations for $48 \mathrm{~h}$ (Fig 2B). Thus, TC induces apoptosis of CHO cells in time- and dose- 
dependent manners.

TC induced apoptosis of $\mathrm{CHO}$ cells through the mitochondrion-mediated apoptotic pathway

A number of stimuli, including stress, chemotherapeutic agents and UV radiation, appear to induce apoptosis via mitochondrial pathway[3, 16, 17]. In the present studies, the molecular changes related to the mitochondrion-regulated apoptotic pathway in TCtreated CHO cells were analyzed. After TC treatment, the cells attaching on the plates, of which there were few of apoptotic cells, and the cells floating in the medium, all of which were apoptotic cells, were collected respectively. The cytosolic fractions and in- soluble fractions containing cellular organelles (mitochondrion-containing fractions) were isolated with digitonin-permeabilization assay[18]. Western blot results showed that cytochrome $\mathrm{c}$ was released from mitochondria to the cytosol in the floating cells, while it remained in the mitochondria of the adherent cells and the cells without the drug treatment (Fig 3, compare lanes 3, 6 and 9 to lanes 2, 5 and 8). Furthermore, all the Bax proteins were translocated from the cytosol to mitochondria in the floating cells, whereas few of Bax proteins were translocated in the adherent cells (Fig 3, compare lanes 5 and 8 to 6 and 9). COX4 (cytochrome c oxidase IV), a mitochondrial membrane protein, served as a control to show no cross
A

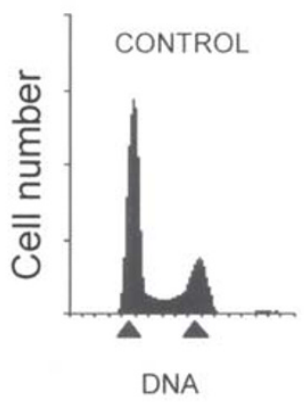

B

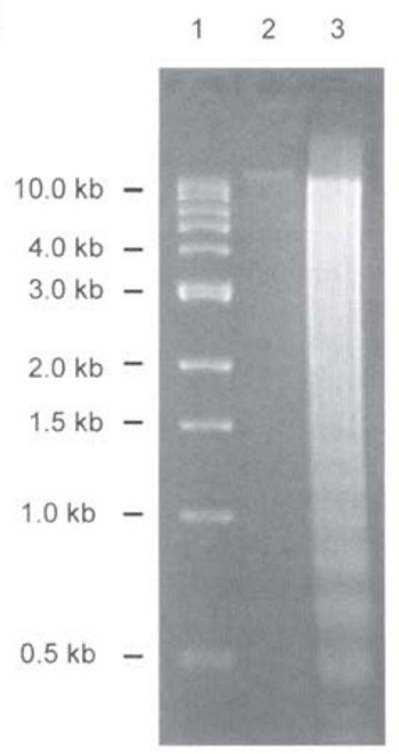

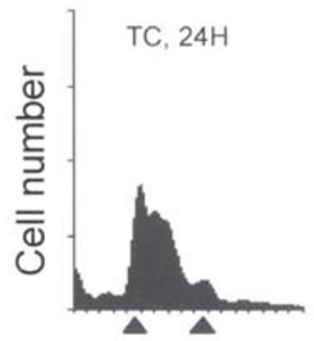

DNA

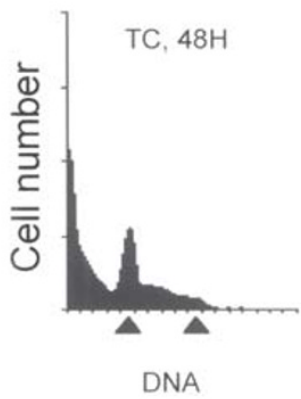

C
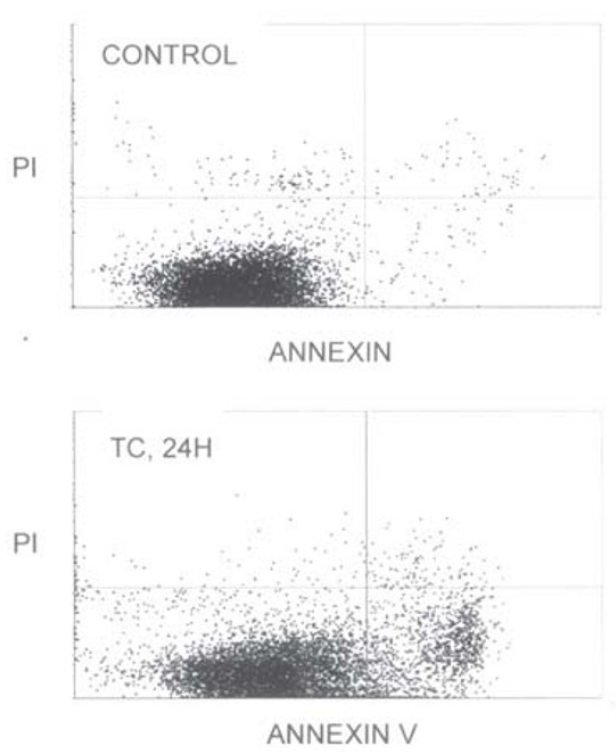

Fig 1. TC induces apoptosis of CHOC400 cells. (A), Flow cytometric analysis of CHO cells. Exponentially growing cells were incubated with $20 \mathrm{ng} / \mathrm{ml}$ of TC for 24 or $48 \mathrm{~h}$ and then analyzed by FACS. The arrowheads indicate DNA contents of $2 \mathrm{~N}$ and $4 \mathrm{~N}$. (B), DNA fragmentation. Lane 1, molecule-weight marker; lane 2, control; lane 3, TC treatment for $24 \mathrm{~h}$. (C), Flow cytometric analysis with Annexin V-PI double staining assay. The population of cells in the right-bottom (PI-negative, Annexin V-poistive) is corresponding to apoptotic cells. 

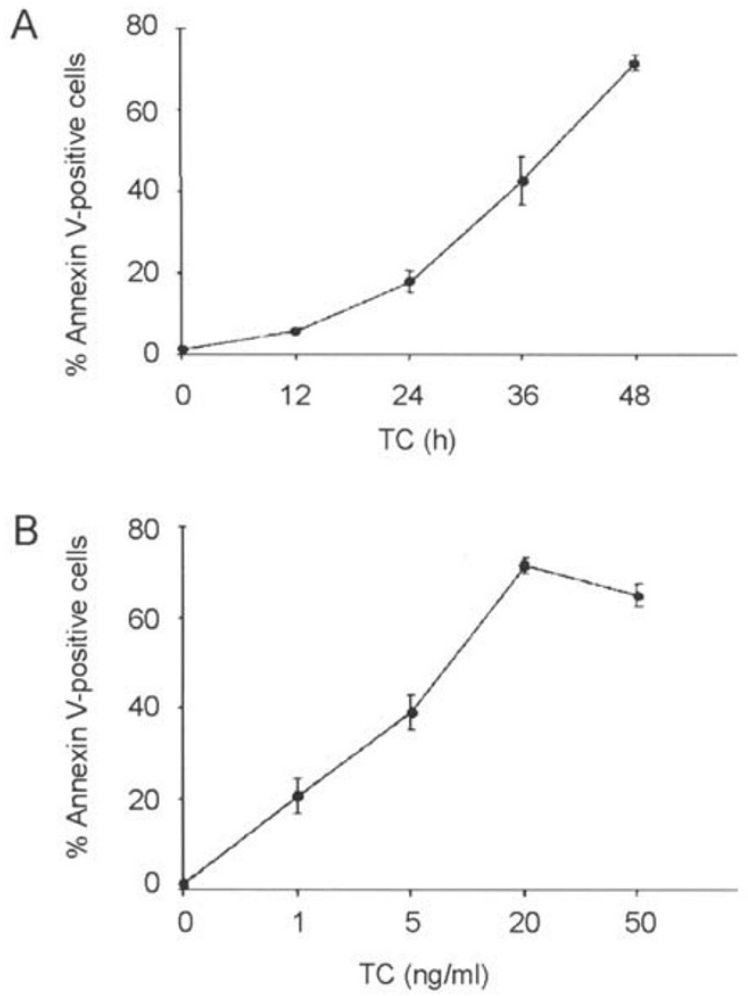

Fig 2. Apoptosis induced by TC is time- and dose-dependent. (A), Exponentially growing CHOC400 cells were treated with TC $(20 \mathrm{ng} / \mathrm{ml})$ for indicated time, and then apoptotic cells were calculated by Annexin V-PI double staining assay. (B), Exponentially growing CHOC400 cell were treated with indicated dose of TC for $48 \mathrm{~h}$. Three independent experiments are averaged, and data are expressed as the mean \pm SD.

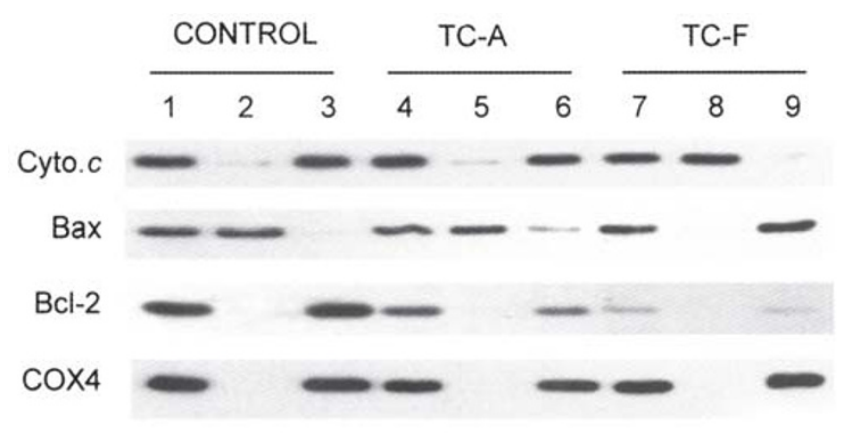

Fig 3. TC induces the release of cytochrome $c$, the translocation of Bax, and the degradation of Bcl-2. Exponentially growing CHOC400 cells were treated with TC $(20 \mathrm{ng} / \mathrm{ml})$ for $24 \mathrm{~h}$, and then adherent cells (TC-A) and floating cells (TC-F) were collected respectively. Total cell lysates (lane 1, 4 and 7), the cytosolic fractions (lane 2, 5 and 8) and mitochondrion-containing fractions (lane 3, 6 and 9) were obtained and analyzed by Western blot as described in materials and methods.
A

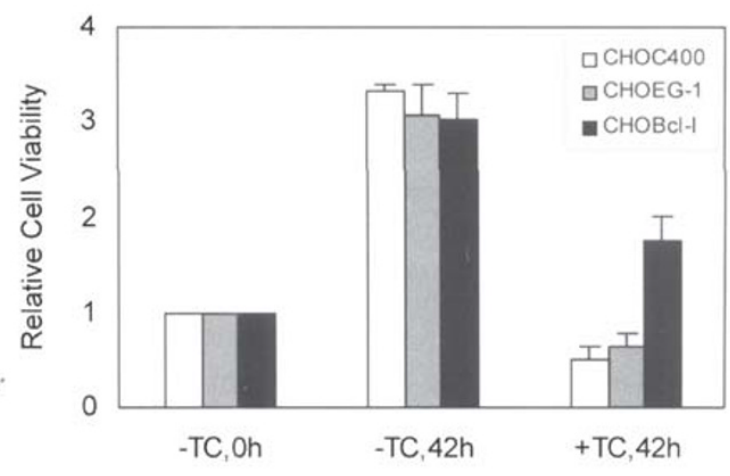

B

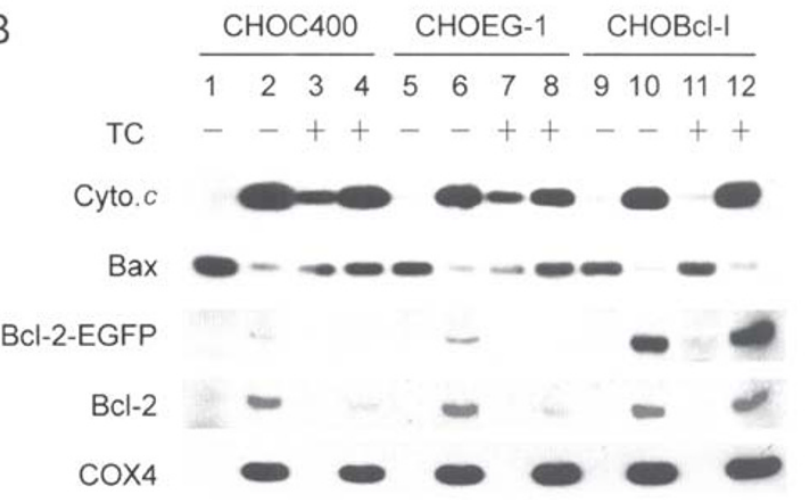

Fig 4. Effects of Bcl-2 over-expression on $\mathrm{CHO}$ cells. (A), Overexpression of Bcl-2 in CHOC400 cells inhibits TC-induced apoptosis. Two cell lines, CHOBcl-I expressing Human Bcl-2EGFP fusion protein and CHOEG-1 only expressing EGFP protein, were isolated as described in materials and methods. CHOC400, CHOBcl-I and CHOEG-1 were incubated with 10 $\mathrm{ng} / \mathrm{ml} \mathrm{TC}$ for $42 \mathrm{~h}$, and then the cell viability was measured by MTT assay. Relative cell viability is calculated in comparison to cell viability at $0 \mathrm{~h}$. Three independent experiments are averaged, and data are expressed as the mean盨D. (B), Overexpression of Bcl-2 inhibits cytochrome $c$ release and Bax mitochondrion-translocation. The cells were incubated with $10 \mathrm{ng} /$ $\mathrm{ml} \mathrm{TC}$ for $42 \mathrm{~h}$, and then all cells, including adherent cells and floating cells, were collected. The cytosolic fractions (lane 1, 3, 5, 7, 9 and 11) and mitochondrion-containing fractions (lane 2, 4, 6, 8, 10 and 12) were obtained and analyzed by western blot as described in materials and methods.

contaminants between mitochondrion-containing fractions and cytosolic fractions (Fig 3). Recently, some experiments have indicated that the translocation of Bax from cytosol to mitochondria resulted in the release of cytochrome $\mathrm{c}$ from the mitochondria during the process of apoptosis[19-21]. Our data were consistent with these observations.

We also found that the amount of Bcl-2 protein was reduced significantly in the floating cells, whereas COX4, as a internal control, had no changes in quan- 
tity (Fig 3), suggesting the degradation of Bcl-2 plays a role in activation of apoptosis of TC-treated $\mathrm{CHO}$ cells. Interestingly, the protein level of Bcl-2 decreased to about $50 \%$ in adherent cells, whereas little amount of Bax was translocated yet (Fig 3, compare lanes 1, 2 and 3 to lanes 45 , and 6), suggesting the degradation of Bcl-2 is prior to Bax translocation during TC-induced apoptosis.

\section{Over-expression of Bcl-2 inhibited TC induced apoptosis}

To investigate the role of Bcl-2 in TC-induced apoptosis of CHO cells, a stable cell line over-expressing human Bcl-2-EGFP fusion protein, CHOBcl-I, was constructed (see materials and methods). The cell viability of different $\mathrm{CHO}$ cell lines in the presence of TC was measured by MTT assay (see materials and methods). The results indicated that TC-induced apoptosis of CHOBcl-I cells was reduced significantly compared to the apoptosis of wild-type $\mathrm{CHO}$ cells or CHOEG-1 cells expressing only EGFP proteins (Fig $4 \mathrm{~A})$. Western-blot experiments showed that release of cytochrome $\mathrm{c}$ from mitochondria, translocation of Bax to mitochondria and degradation of Bcl-2 were all inhibited in TC-treated CHOBcl-I cells (Fig 4B). Taken together, these results suggested that over-expression of Bcl-2 could block TC-induced apoptosis by inhibiting the translocation of Bax from cytosol to mitochondria.

\section{DISCUSSION}

Recent reports showed that triptolide, another compound also isolated from Tripterygium Wilfordii Hook. f., could enhance the apoptosis indirectly[12, 13]. For example, triptolide increased doxorubicin-induced apoptosis of tumor cells through blocking p53dependent p21 transcription[13]. However, our present studies showed that TC can induce the apoptosis directly. Comet assay showed that TC resulted in DNA damage of CHOC400 cells (data not shown). Moreover, UV41 cell line, which is deficient in the ERCC4 gene encoding a nucleotide repair protein, was much more sensitive to TC-treatment than the normal CHO cells (data not shown, see reference [22]). These results suggest that TC causes DNA damage and then triggers the apoptotic program of CHO cells.
It has been hypothesized that the ratio of $\mathrm{Bcl}-2 / \mathrm{Bax}$ determines the response to apoptotic signals[5]. In the present experiments, the results showed that the degradation of Bcl-2 was prior to the Bax translocation from cytosol to mitochondria in apoptotic cells (see Fig 3 ), while over-expression of Bcl-2 inhibited the mitochondrial translocation of Bax (see Fig 4). It should be interesting to know how the Bcl-2 protein inhibits the Bax mitochondrial translocation. Some experiments suggested that Bcl-2 might inhibit an upstream event necessary for Bax conformational change[23], which was required for the translocation of $\operatorname{Bax}[24$, 25]. While, other reports suggested that Bcl-2 might abort Bax-induced apoptotic events by blocking its oligomerization on mitochondrial membrane[26, 27]. However, another possible mechanism of inhibition of Bax by Bcl-2 is that Bcl-2 molecules prevent the binding of Bax to the limited insertion sites in the mitochondrial membrane, and the degradation of Bcl2 leaves enough space for Bax insertion.

\section{ACKNOWLEDGEMENTS}

We thank Dr. Yuan Chao LI of Institute of Materia Medica, SIBS, CAS who provided TC compound. This work was supported by Grant 39825115 of the National Outstanding Young Scientists, a special grant of major state basic research program of China (No. G1999053901), and a grant from the Chinese Academy of Sciences KSCX2-SW-203 to JR Wu.

\section{REFERENCES}

1. Jacobson MD, Weil M, Raff MC. Programmed Cell Death in Animal Development. Cell 1997; 88:347-54.

2. White E. Life, death and pursuit of apoptosis. Genes Dev 1996; 10:1-15.

3. Wang $\mathrm{X}$. The expanding role of mitochondria in apoptosis. Genes Dev 2001; 15:2922-33.

4. Geng YJ. Molecular signal transduction in vascular cell apoptosis. Cell Res 2001; 11:253-64.

5. Chao DT, Korsmeyer SJ. Bcl-2 family: regulators of cell death. Annu Rev Immunol 1998; 16:395-419.

6. Matthew G., Heiden V, Thompson CB. Bcl-2 proteins: regulators of apoptosis or of mitochondrial homeostasis? Nature Cell Biol 1999; 1:E209-16.

7. Antonsson B, Martinou J. The Bcl-2 protein family. Exp Cell Res 2000; 256:50-7.

8. Budihardho I, Oliver H, Lutter M, Xu L, Wang X. Biochemical pathways of caspase activation during apoptosis. Annu Rev Cell Dev Biol 1999; 15:269-90.

9. Lu X, Ma P, Chen T et al. The isolation and structure of tripcholrolide (T4) from Tripterygium Wilfordii. Acta 
Academiae Medicinae Sinicae 1990; 12:157-61.

10. Qian SZ, Xu Y, Zhang JW. Recent progress in research on Tripterygium: a male antifertility plant. Contraception 1995; 51:121-9.

11. Zhang T, Chen Z, Lin C. Antineoplastic action of triptolide and its effect on the immunologic functions in mice. Acta Pharm Sinica 1981; 2:128-31.

12. Lee KY, Chang W, Qiu D, Kao PN, Rosen GD. PG490 (triptolide) cooperates with tumor necrosis factor-a to induce apoptosis in tumor cells. J Biol Chem 1999; 274:134515.

13. Chang W, Kang JJ, Lee K et al. Triptolide and chemotherapy cooperate in tumor cell apoptosis. J Biol Chem 2001; 276: 2221-7.

14. Zhang J, Xu M. DNA fragmentation in apoptosis. Cell Res 2000; 10:205-11.

15. Vermes I, Haanen C, Steffens-Nakken H, Reutelingsperger C. A novel assay for apoptosis. Flow cytometric detection of phosphatidylserine expression on early apoptotic cells using fluorescein labelled Annexin V. J Immunol Methods 1995; 184:39-51.

16. Green DR, Reed JC. Mitochondria and apoptosis. Science 1998; 281:1309-12.

17. Guo BC, Xu YH. Bcl-2 over-expression and activation of protein kinase $\mathrm{C}$ suppress the trail-induced apoptosis in Jurkat T cells. Cell Res 2001; 11:101-6.

18. Gottlieb RA, Granville DJ. Analyzing mitochondrial changes during apoptosis. Methods 2002; 26:341-7.

19. Khaled AR, Kim K, Hofmeister R, Muegge K, Durum SK. Withdrawal of IL-7 induces Bax translocation from cytosol to mitochondria through a rise in intracellular $\mathrm{pH}$. Proc Natl Acad Sci USA 1999; 96:14476-81.

20. Gross A, Jockel J, Wie MC, Korsmeyer SJ. Enforced dimerization of Bax results in its translocation, mitochondrail dysfunction and apoptosis. EMBO J 1998; 17:3878-85.

21. Jü gensmeier JM, Xie Z, Deveraux Q, Ellerby L, Bredesen D, Reed JC. Bax directly induces release of cytochrome $\mathrm{c}$ from isolated mitochondria. Proc Natl Acad Sci USA 1998; 95: 4997-5002.

22. Jiang MR, Li YC, Yang Y, Wu JR. c-Myc degradation induced by DNA damage results in apoptosis of CHO cells. Oncogene 2003; 22:3252-9.

23. Murphy K, Streips UN, Lock RB. Bcl-2 inhibits a Fas-induced conformational change in the Bax $\mathrm{N}$ terminus and Bax mitochondrial translocation. J Biol Chem 2000; 275: 17225-8.

24. Khaled AR, Kim K, Hofmeister R, Muegge K, Durum SK. Withdrawal of IL-7 induces Bax translocation from cytosol to mitochondria through a rise in intracellular $\mathrm{pH}$. Proc Natl Acad Sci USA 1999; 96:14476-81.

25. Suzuki M, Youle RJ, Tjandra N. Structure of Bax: coregulation of dimmer formation and intracellular localization. Cell 2000; 103:645-54.

26. Sundararajan R, White E. E1b 19k blocks bax oligomerization and tumor necrosis factor alpha-mediated apoptosis. $\mathrm{J}$ Virol 2001; 75:7506-16.

27. Wei MC, Zong WX, Cheng EH, et al. Proapoptotic BAX and BAK: A requisite gateway to mitochondrial dysfunction and death. Science 2001; 292:727-30. 